\title{
Complex translocation involving four chromosomes in a novel Philadelphia-positive chronic myeloid leukemia case
}

\author{
WALID AL-ACHKAR ${ }^{1}$, ABDULSAMAD WAFA ${ }^{1}$ and THOMAS LIEHR ${ }^{2}$ \\ ${ }^{1}$ Molecular Biology and Biotechnology Department, Human Genetics Division, Atomic Energy Commission, \\ Damascus, Syria; ${ }^{2}$ Jena University Hospital, Institute of Human Genetics, Jena, Germany
}

Received August 19, 2010; Accepted December 13, 2010

DOI: $10.3892 / \mathrm{ol} .2011 .257$

\begin{abstract}
The so-called Philadelphia ( $\mathrm{Ph}$ ) chromosome is present in more than $90 \%$ of chronic myeloid leukemia (CML) cases. Approximately $5-10 \%$ of these patients show complex translocations involving a third chromosome in addition to chromosomes 9 and 22. Since the majority of CML cases are currently treated with imatinib, variant rearrangements in general have no specific prognostic significance, although the mechanisms involved in resistance to therapy have yet to be investigated. This study evalutated a CML case with complex chromosomal aberrations not previously observed. A four chromosome translocation involving chromosomal regions such as $12 \mathrm{q} 24.2-24.31$ and $16 \mathrm{p} 11.2$ besides $9 \mathrm{q} 34$ and 22 q11 were characterized in detail by array-proven multicolor banding (aMCB). A beneficial response to imatinib was noted in the patient.
\end{abstract}

\section{Introduction}

Chronic myeloid leukemia (CML) is a myeloproliferative disease that originates in abnormal pluripotent bone marrow stem cells and is consistently associated with the Philadelphia (Ph) chromosome which normally leads to BCR/ABL gene fusion (1). The $\mathrm{Ph}$ chromosome created as a result of $\mathrm{t}(9 ; 22)$ (q34;q11) is observed in more than $90 \%$ of CML patients. The $\mathrm{BCR}-\mathrm{ABL}$ fusion gene is formed by the transposing of the $3^{\prime}$ portion of the ABL oncogene from $9 \mathrm{q} 34$ to the $5^{\prime}$ portion of the BCR gene on chromosome 22, and this fusion gene encodes a constitutive active tyrosine kinase (2). Masked or variant $\mathrm{Ph}$ translocations characterize 5-10\% of CML cases. A masked $\mathrm{Ph}$ chromosome is found in cases with a normal karyotype, as a result of a cryptic rearrangement, or in patients

Correspondence to: Dr Walid Al-Achkar, Molecular Biology and Biotechnology Department, Human Genetics Division, Atomic Energy Commission of Syria, P.O. Box 6091, Damascus, Syria E-mail: ascientific@aec.org.sy

Key words: chronic myeloid leukemia, variant Philadelphia chromosome, fluorescence in situ hybridization, high-resolution array-proven multicolor banding, imatinib mesylate with complex changes where the typical $\mathrm{t}(9 ; 22)$ (q34; 111$)$ is not detectable by G-banding (3). These rearrangements are detected by fluorescence in situ hybridization (FISH) (4). The variant $\mathrm{Ph}$ translocation is cytogenetically classified as involving chromosomes 9 and 22, as well as one or more other chromosomes $(5,6)$. Imatinib mesylate (Glivec, formerly STI571) was designed specifically to inhibit the tyrosine kinase activity of the BCR/ABL protein and other tyrosine kinases such as $\mathrm{cABL}$, c-KIT and PDGF (platelet-derived growth factor receptor). By binding to an active site of the tyrosine kinase, Glivec switches off downstream signaling, cells stop proliferating and apoptosis ensues (7). Various studies showed a high efficiency of imatinib therapy to achieve a complete or major cytogenetic response, i.e., a reduction to $0-34 \% \mathrm{Ph}$-positive cells. This positive effect is achieved in cases with a simple $\mathrm{t}(9 ; 22)$ combined with complex translocations resulting in $\mathrm{BCR} / \mathrm{ABL}$ gene fusion, as well as in cases with cytogenetic clonal evolution $(8,9)$.

This study investigated a novel $\mathrm{Ph}$ chromosome-positive CML case with a new complex rearrangement formed by four chromosomes and new complex aberrations involving four chromosomal breakpoints. Treatment with imatinib proved successful. In this case, the high-resolution array-proven multicolor banding (aMCB) technique was crucial in the detection of genetic changes.

\section{Materials and methods}

Case report. A 43-year-old female was diagnosed as suffering from CML in the chronic phase (CP) following a blood cell count that was initiated in January 2004 due to a white blood cell count (WBC) of $8.0 \times 10^{9} / 1$ and fever. The patient was treated with imatinib mesylate at a dose of $400 \mathrm{mg} /$ day overall for 10 months. During that period the patient showed no symptoms. However, in July 2006, the patient presented for the second time with a WBC of $4.8 \times 10^{9} / 1$ consisting of $61 \%$ neutrophils, $38 \%$ lymphocytes and $1 \%$ immature cells. The platelet count was $375 \times 10^{9} / 1$ and the hemoglobin level was $12.1 \mathrm{~g} / \mathrm{dl}$. The patient was treated with imatinib mesylate at a dose of $400 \mathrm{mg} /$ day overall for 30 months. A physical examination revealed no hepatomegaly or splenomegaly, and a bone marrow trephine did not show any fibrosis. The patient was lost during follow-up. In August 2009, she succumbed to unknown causes. 


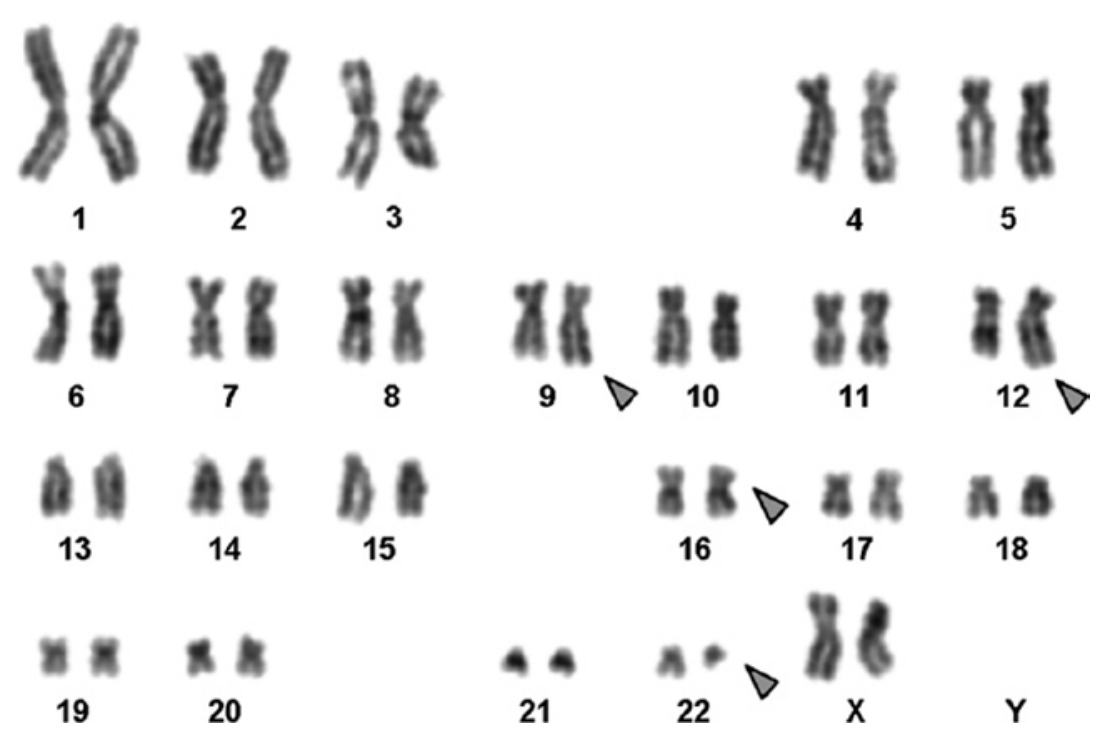

Figure 1. GTG-banding showed a complex karyotype involving two further chromosomes besides chromosomes 9 and 22. Derivative chromosomes are indicated by the arrowheads.

Cytogenetic analysis. Chromosome analysis using GTGbanding was performed according to standard procedures (10). A total of 20 metaphases derived from the unstimulated bone marrow of the patient were analyzed. Karyotypes were described according to the International System for Human Cytogenetic Nomenclature (11).

Molecular cytogenetics. FISH using a LSI BCR/ABL dualcolor dual fusion translocation probe (Abbott Molecular/Vysis, USA), whole chromosome painting (WCP) probe for chromosomes 12, 16 and 22 (MetaSystems, Altlussheim, Germany) and an alpha satellite probe (CEP) for chromosome 9 (Abbott Molecular/Vysis) were applied according to the manufacturer's instructions (12). Array-proven multicolor banding probe (aMCB) sets based on microdissection-derived region-specific libraries for chromosomes 9, 12, 16 and 22 were applied as previously described $(13,14)$. A total of 20 metaphase spreads were analyzed, using a fluorescence microscope (AxioImager. Z1 mot, Zeiss) equipped with appropriate filter sets to distinguish between a maximum of five fluorochromes and the counterstain DAPI (4',6-diamino-2-phenylindole). Image capturing and processing were carried out using an ISIS imaging system (MetaSystems) for the MCB evaluation.

\section{Results}

Karyotyping was performed following the initiation of chemotherapy treatment, with various karyotypic changes. A complex karyotype $46, \mathrm{XX}, \mathrm{t}(9 ; 12 ; 16 ; 22) / 46, \mathrm{XX}$ was determined in the GTG-banding (Fig. 1) and was further specified by molecular cytogenetic studies (Figs. 2 and 3). A dual-color FISH using a probe specific for $\mathrm{BCR}$ and $\mathrm{ABL}$ revealed a typical $\mathrm{Ph}$ chromosome with the BCR/ABL fusion gene (Fig. 2A). Dualcolor FISH using WCP- and CEP-specific probes was applied to evidence further rearrangements (Figs. 2B and D). Thus, the chromosomes 9, 12, 16 and 22 were found to be involved in the karyotypic changes. aMCB using probes for the corre- sponding chromosomes was performed as previously reported (14). A complex translocation among the four chromosomes was detected (Fig. 3), and the final karyotypes obtained were: $46, X X, t(9 ; 12 ; 16 ; 22)(q 34 ; q 24.2 \sim 24.31 ; p 11.2 ; q 11)[12] /$ $46, \mathrm{XX}[8]$.

\section{Discussion}

We described a novel Philadelphia $(\mathrm{Ph})$ chromosome-positive CML case with the new complex variant translocation $\mathrm{t}(9 ; 12 ; 16 ; 22)(\mathrm{q} 34 ; \mathrm{q} 24.2-24.31 ; \mathrm{p} 11.2 ; \mathrm{q} 11)$. To the best of our knowledge, this translocation has never previously been observed in CML (15).

In 5-10\% of Ph chromosome-positive CML cases, complex translocations are noted in both chromosomes 9 and 22 and other chromosomes, such as 12 and 16 (3). At present, it appears that variant translocations are able to affect any chromosome. However, it has been suggested that the distribution of the breakpoints is non-random, with the chromosomal bands most susceptible to breakage being 1p36, 3p21, 5q31, 6p21, 9q22, 10q22, 11q13, 12p13, 17p13, 17q21, 17q25, 19q13, 21q22, 22q12 and $22 \mathrm{q} 13$ (1).

Two potential mechanisms for variant translocation formation have been suggested. The first is a single-event rearrangement via the simultaneous breakage of a number of chromosomes followed by mismatched joining (6). Nacheva et al proposed a classical $\mathrm{Ph}$ translocation followed by further translocation between chromosomes 9 and 22, in addition to a third chromosome (16). The mechanism of the formation of a variant $\mathrm{Ph}$ translocation may have prognostic importance in that a two-event mechanism indicates clonal evolution, whereas a variant translocation occurring via a single genomic rearrangement may confer a similar prognosis to the classical Ph translocation (17).

In conclusion, we report a novel case of a $\mathrm{Ph}$ chromosome-positive $\mathrm{CML}$ in $\mathrm{CP}$ with a new complex variant $\mathrm{Ph}$ translocation involving the four chromosomal aberrations of 


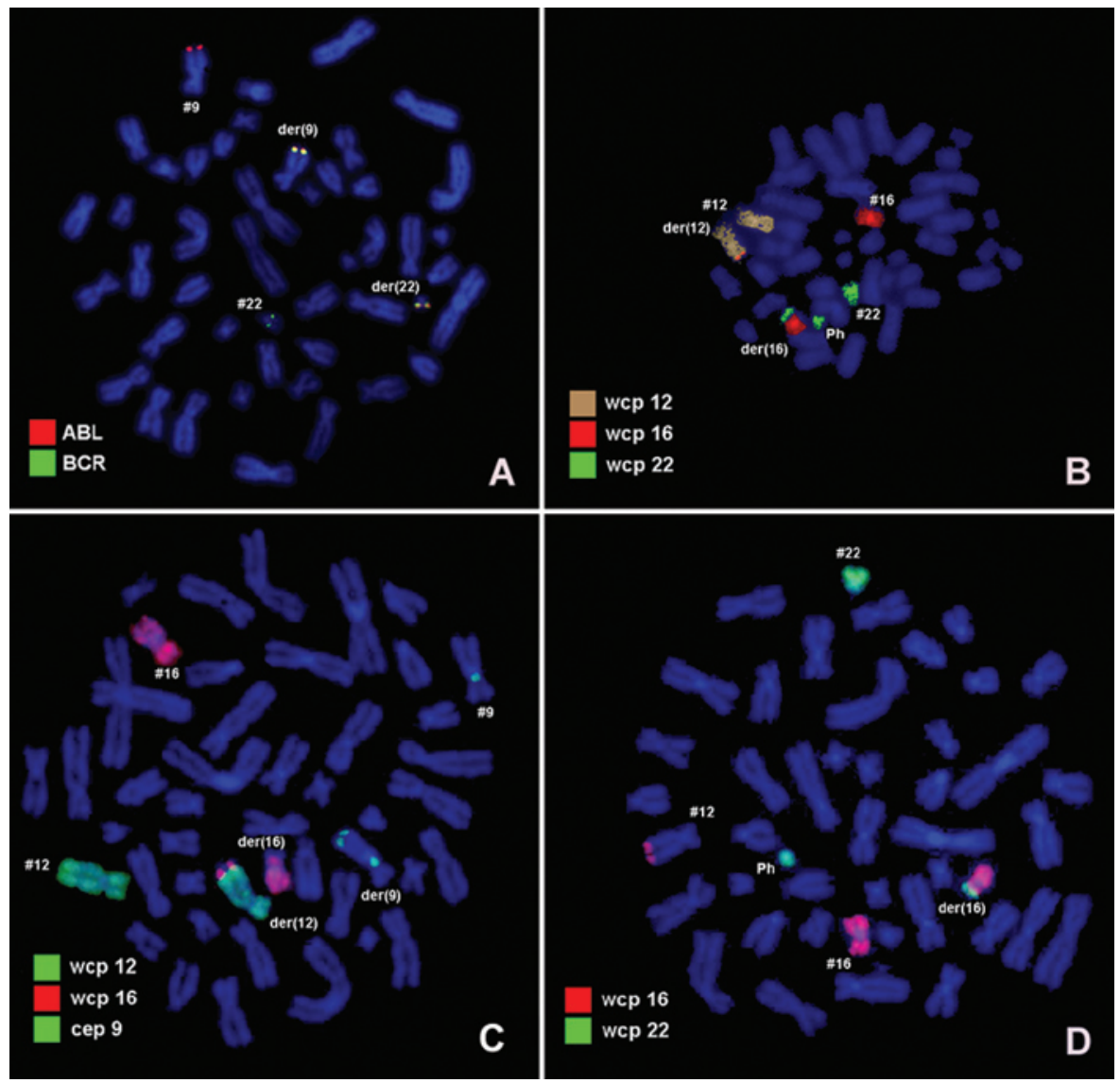

Figure 2. Karyotype and chromosomal aberrations were confirmed using molecular cytogenetic approaches. (A) Fluorescence in situ hybridization (FISH) using probes for BCR (green) and ABL (red) confirmed the presence of the BCR/ABL translocation and the Philadelphia (Ph) chromosome. The der(9) shows material, in DAPI, which was identified as chromosome 12 (image not shown) and detected using the LSI BCR/ABL dual-color dual-fusion translocation probe. (B-D) The application of FISH analysis using WCP and CEP probe sets for chromosomes 9, 12, 16 and 22 are shown. \#, chromosome; der, derivative chromosome; Ph, Philadephia chromosome.

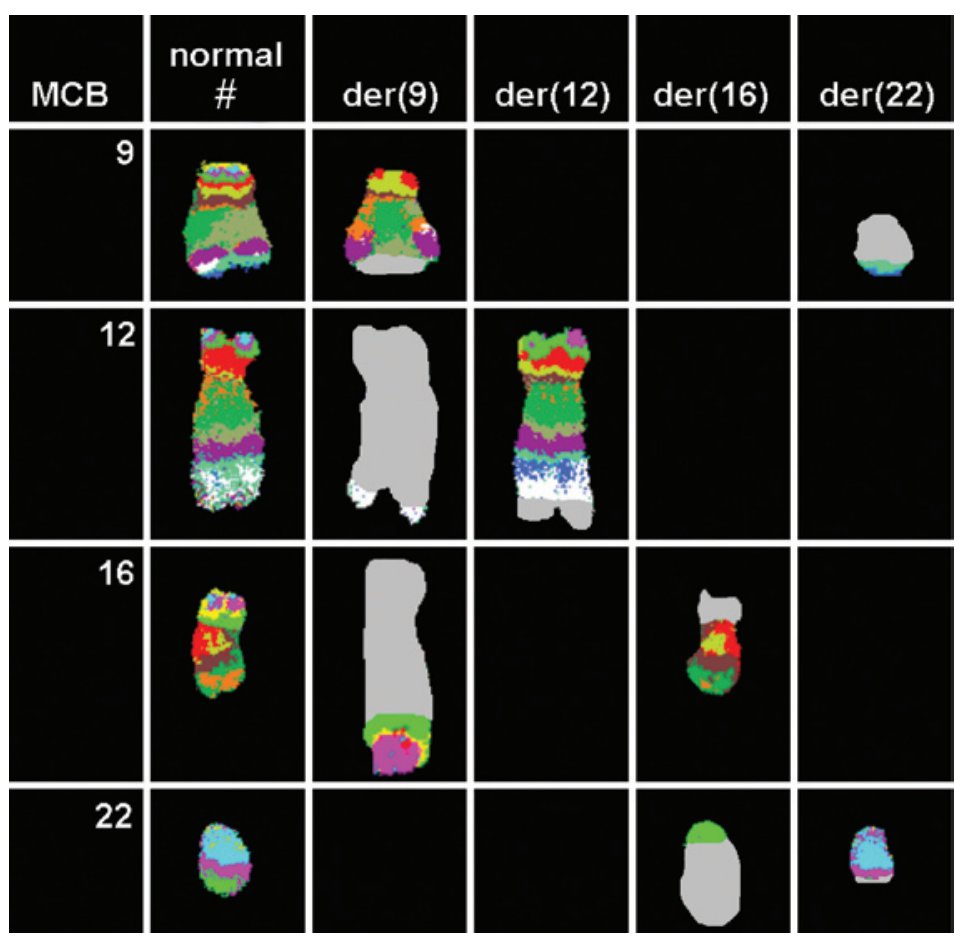

Figure 3. Array-proven multicolor banding (aMCB) was applied to determine which chromosomes were involved in the complex rearrangement. Each lane shows the results of aMCB analysis using probe sets for chromosomes 9, 12, 16 and 22. The normal chromosomes are shown in the first column and the derivative of four chromosomes in subsequent ones. The aMCB-probe unstained regions on the derivative chromosomes are shown in gray. \#, chromosome; der, derivative chromosome. 
9q34, q24.2-24.31, 16p11.2 and 22q11. Notably, the reported patient had a beneficial response to imatinib, although she succumbed to unknown causes.

\section{Acknowledgements}

We thank Professor I. Othman, Director General of Atomic Energy Commission of Syria (AECS), and Dr N. Mirali, Head of Molecular Biology and Biotechnology Department, for their support. This study was supported by the AECS, and in parts by the Stefan-Morsch-Stiftung, Monika-Kutzner-Stiftung and the DAAD (D/07/09624).

\section{References}

1. Johansson B, Fioretos T and Mitelman F: Cytogenetic and molecular genetic evolution of chronic myeloid leukemia. Acta Haematol 107: 76-94, 2002.

2. Shtivelman E, Lifshitz B, Gale RP and Canaani E: Fused transcript of abl and bcr genes in chronic myelogenous leukemia Nature 315: 550-554, 1985.

3. La Starza R, Testoni N, Lafage-Pochitaloff M, Ruggeri D, Ottaviani E, Perla G, Martelli MF, Marynen P and Mecucci C: Complex variant Philadelphia translocations involving the short arm of chromosome 6 in chronic myeloid leukemia Haematologica 87: 143-147, 2002.

4. Todorić-Zivanović B, Marisavljević D, Surace C, Cemerikić V, Marković O, Krtolica K, Tatomirović Z, Cikota B, Magić Z and Rocchi M: A Ph-negative chronic myeloid leukemia with a complex BCR/ABL rearrangement and a $\mathrm{t}(6 ; 9)(\mathrm{p} 21 ; \mathrm{q} 34.1)$. Cancer Genet Cytogenet 166: 180-185, 2006.

5. Naumann S and Decker HJ: Genesis of variant Philadelphia chromosome translocations in chronic myelocytic leukemia. Cancer Genet Cytogenet 147: 18-22, 2003.

6. Fitzgerald PH and Morris CM: Complex chromosomal translocations in the Philadelphia chromosome leukemias. Serial translocations or a concerted genomic rearrangement? Cancer Genet Cytogenet 57: 143-151, 1991.

7. Griffen J: The biology of signal transduction The biology of signal transduction inhibition: basic science to novel therapies. Semin Oncol 28: 3-8, 2001.

8. Kantarjian H, Sawyers C, Hochhaus A, Guilhot F, Schiffer C, Gambacorti-Passerini C, Niederwieser D, Resta D, Capdeville R, Zoellner U, Talpaz M, Druker B, Goldman J, O'Brien SG, Russell N, Fischer T, Ottmann O, Cony-Makhoul P, Facon T, Stone R, Miller C, Tallman M, Brown R, Schuster M, Loughran T, Gratwohl A, Mandelli F, Saglio G, Lazzarino M, Russo D, Baccarani M and Morra E: International STI571 CML Study Group: Hematologic and cytogenetic responses to imatinib mesylate in chronic myelogenous leukemia. N Engl J Med 346 : 645-652, 2002.
9. Cortes JE, Talpaz M, Giles F, O'Brien S, Rios MB, Shan J, Garcia-Manero G, Faderl S, Thomas DA, Wierda W, Ferrajoli A, Jeha S and Kantarjian HM: Prognostic significance of cytogenetic clonal evolution in patients with chronic myelogenous leukemia on imatinib mesylate therapy. Blood 101: 3794-3800, 2003.

10. Claussen U, Michel S, Mühlig P, Westermann M, Grummt UW, Kromeyer-Hauschild K and Liehr T: Demystifying chromosome preparation and the implications for the concept of chromosome condensation during mitosis. Cytogenet Genome Res 98: 136-146, 2002.

11. Shaffer L, Slovak M and Cambell L (eds): ISCN (2009): An International System for Human Cytogenetic Nomenclature. S. Karger, Basel, 2009.

12. Al-Achkar W, Wafa A and Nweder MS: A complex translocation $\mathrm{t}(5 ; 9 ; 22)$ in Philadelphia cells involving the short arm of chromosome 5 in a case of chronic myelogenous leukemia. J Exp Clin Cancer Res 26: 411-415, 2007.

13. Weise A, Mrasek K, Fickelscher I, Claussen U, Cheung SW, Cai WW, Liehr T and Kosyakova N: Molecular definition of high-resolution multicolor banding probes: first within the human DNA sequence anchored FISH banding probe set. J Histochem Cytochem 56: 487-493, 2008.

14. Liehr T, Heller A, Starke H, Rubtsov N, Trifonov V, Mrasek K, Weise A, Kuechler A and Claussen U: Microdissection based high resolution multicolor banding for all 24 human chromosomes. Int J Mol Med 9: 335-339, 2002.

15. Mitelman F, Johansson B and Mertens F (eds): Mitelman Database of Chromosome Aberrations in Cancer, 2009. http:// cgap.nci.nih.gov/Chromosomes/Mitelman.

16. Nacheva E, Holloway T, Brown K, Bloxham D and Green AR: Philadelphia-negative chronic myeloid leukaemia: detection by FISH of BCR-ABL fusion gene localized either to chromosome 9 or chromosome 22. Br J Haematol 87: 409-412, 1994.

17. Reid AG, Huntly BJP, Grace C, Green AR and Nacheva EP: Survival implications of molecular heterogeneity in variant Philadelphia-positive chronic myeloid leukaemia. Br J Haematol 121: 419-427, 2003. 